\title{
Cobertura do solo, produção de biomassa e acúmulo de nutrientes por plantas de cobertura
}

\author{
Canopy cover, biomass production and nutrient accumulation by coper crops
}

\section{Neuro Hilton Wolschick ${ }^{1}$, Fabrício Tondello Barbosa ${ }^{1 *}$, Ildegardis Bertol ${ }^{1}$, Kristiana Fiorentin dos Santos$^{2}$, Romeu de Souza Werner ${ }^{1}$ e Bárbara Bagio ${ }^{1}$}

Recebido em 03/08/2015 / Aceito em 13/04/2016

\section{RESUMO}

A utilização de plantas de cobertura do solo é importante estratégia para manutenção da capacidade produtiva de áreas agrícolas. A pesquisa objetivou determinar a cobertura do solo, a produção de fitomassa e o acúmulo de $\mathrm{N}, \mathrm{P}, \mathrm{K}, \mathrm{Ca}$ e $\mathrm{Mg}$ no tecido vegetal de diferentes espécies de plantas de cobertura no Planalto Sul Catarinense. O experimento foi conduzido em um Cambissolo Húmico e foram avaliados os tratamentos: i) AP - aveia preta (Avena strigosa); ii) NF - nabo forrageiro (Raphanus sativus L.); iii) EC - ervilhaca comum (Vicia sativa); iv) CE - consórcio das três espécies; e v) PO - pousio com vegetação espontânea. O uso de plantas de cobertura tem potencial para alta produção de biomassa, cobertura pelo dossel e acúmulo de nutrientes pelo tecido vegetal, superior ao pousio de inverno. No início do desenvolvimento vegetal maior taxa de crescimento e cobertura do solo ocorrem em NF e CE, enquanto ao final destacam-se EC e CE. Os cultivos de $\mathrm{AP}, \mathrm{EC}$ e CE produzem maiores quantidades de massa seca de parte aérea e o de AP produz maior massa de raízes. No geral, os tratamentos $\mathrm{EC}$ e $\mathrm{CE}$ e a parte aérea das plantas acumulam mais nutrientes no tecido vegetal em comparação aos demais tratamentos e as raízes, respectivamente.

PALAVRAS-CHAVE: conservação do solo, consórcio de espécies, adubação verde, ciclagem de nutrientes.

\section{ABSTRACT}

The use of cover crops is an important strategy for maintaining the productive capacity of agricultural land. This research aimed to determine the soil coverage, biomass production and accumulation of $\mathrm{N}$, $\mathrm{P}, \mathrm{K}, \mathrm{Ca}$ and $\mathrm{Mg}$ in plant tissue of different species of cover crops on the southern plateau of Santa Catarina, Brazil. The experiment was conducted in a Humic Cambisol (Inceptisol) with the following treatments: i) BO - black oat (Avena strigosa); ii) WR - wild radish (Raphanus sativus L.); iii) CV - common vetch (Vicia sativa); iv) IS - intercropping of the three species; and v) WF - winter fallow with spontaneous vegetation. The use of cover crops has potential for high biomass production, canopy cover and nutrient accumulation by plant tissue, higher than winter fallow. In the early stage of plant development the highest growth rates and soil coverage occur in WR and IS, while at the end are higher in CV and IS. The crops of BO, CV and IS produce large amounts of dry shoot mass and $\mathrm{BO}$ produces greater dry root mass. In general, the $\mathrm{CV}$ and IS treatments and the shoot accumulate greater amounts of nutrients in plant tissue as compared to other treatments and the roots, respectively.

KEYWORDS: soil conservation, intercropping cover crops, green manure, nutrient cycling.

\section{INTRODUÇÃO}

A utilização de plantas de cobertura é importante para a qualidade física do solo, tanto na proteção da superfície quanto no aporte de fitomassa proveniente da parte aérea e raízes (SOUZA et al. 2014). Além do mais, acumulam nutrientes no material vegetal e os liberam durante sua decomposição, possibilitando manutenção e melhoria da fertilidade do solo (SILVA et al. 2014) e estímulo à atividade biológica pela interação positiva entre plantas e microbiota do solo (REIS et al. 2012). A escolha de espécies vegetais para tais finalidades depende, dentre outras características,

\footnotetext{
${ }^{1}$ Universidade do Estado de Santa Catarina, Lages, SC, Brasil.

${ }^{2}$ Universidade Federal de Santa Maria, Santa Maria, RS, Brasil.

*Autor para correspondência <fabriciotondello@gmail.com>
} 
do potencial de produção de fitomassa e da capacidade de absorver e acumular nutrientes (SOUZA \& GUIMARÃES 2013). Essas características têm grande importância no sistema solo-planta por estarem relacionadas à ciclagem de nutrientes, o que aumenta a disponibilidade para as plantas e melhora a eficiência de uso dos fertilizantes (ALBUQUERQUE et al. 2013).

ROSSETTI et al. (2012) observaram melhorias nos atributos físicos da camada superficial do solo e aumento nos teores de matéria orgânica, a qual é fonte de nutrientes para as culturas, pela utilização de plantas de cobertura em comparação ao pousio. Em trabalho realizado por ALCÂNTARA et al. (2000) os autores constataram maiores acúmulos dos elementos $\mathrm{N}, \mathrm{K}, \mathrm{Ca}$ e $\mathrm{Mg}$ na superfície do solo pelo uso de leguminosas como plantas de cobertura em comparação ao uso de gramíneas e atribuiu este efeito a maior capacidade de reciclagem e mobilização de nutrientes no primeiro deles.

A proteção do solo pelas plantas relacionase com o desenvolvimento do dossel, dependente da espécie vegetal (AGOSTINETTO et al. 2000). A velocidade de crescimento e de cobertura do solo influencia a erosão, pois, no início do ciclo as plantas contêm pequena massa vegetal e cobrem pouco o solo, sendo este um período crítico do ponto de vista de erosão (BEZERRA \& CANTALICE 2006).

$\mathrm{O}$ advento da semeadura direta trouxe grandes avanços na redução da erosão hídrica de áreas agrícolas, porém, em muitas situações se observa deficiência de cobertura do solo. Em geral, o monocultivo ou a sucessão de culturas agravam este problema que poderia ser solucionado com o uso de espécies para cobertura do solo antecedendo os cultivos comerciais (WOLSCHICK 2014). No sul do Brasil, a aveia é muito cultivada no período de inverno antecedendo os cultivos de verão. Apesar da importância do uso de leguminosas pela fixação biológica de $\mathrm{N}$ atmosférico, sua utilização ainda é restrita como planta de cobertura. Isso ocorre pelo maior custo de implantação e disponibilidade de sementes no mercado, bem como pelo desenvolvimento inicial lento e rápida decomposição dos resíduos culturais (SILVA et al. 2006). Outra espécie que vem sendo cultivada para cobertura do solo é o nabo forrageiro, cujo crescimento é rápido e oferece boa cobertura do solo, sendo alternativo às espécies de gramíneas e leguminosas (CALEGARI et al. 1993).

Diferentes resultados de produção de biomassa vegetal das mesmas espécies são esperados em locais distintos, devido à variabilidade de solo (DONEDA et al.2012) e clima, peculiares de cada região(RIZZARDI et al. 2006). O uso de plantas de cobertura é necessário para produzir palha e ciclar nutrientes, entretanto, são escassas as informações sobre o desenvolvimento e acúmulo de nutrientes de espécies para as condições do Planalto Sul Catarinense. Pesquisas dessa natureza justificam-se pela necessidade de gerar informações sobre produção de biomassa vegetal aérea e radicular, taxa de crescimento e estatura de plantas e porcentagem de cobertura do solo pelo dossel ou por resíduos culturais, para uso em modelos de predição de erosão já existentes (BERTOL et al. 2014).

Com este trabalho objetivou-se avaliar a cobertura do solo proporcionada pelo dossel vegetativo, a produção de fitomassa de parte aérea e raízes e o acúmulo de nutrientes no tecido vegetal de diferentes espécies de plantas de cobertura do solo no Planalto Sul Catarinense.

\section{MATERIAL E MÉTODOS}

O experimento foi conduzido a campo, em 2013, no Campus III da Universidade do Estado de Santa Catarina, localizado no munícipio de Lages, na região do Planalto Sul de SC (coordenadas 2747'12,9' S e $50^{\circ} 18^{\prime} 25,1$ ” W), a $925 \mathrm{~m}$ de altitude, onde o clima é subtropical úmido mesotérmico, do tipo $\mathrm{Cfb}$ - Köppen (ALVARES et al. 2013). O solo é um Cambissolo Húmico Alumínico léptico, com substrato composto de siltitos e argilitos, classificado de acordo com o sistema brasileiro de classificação de solos - SiBCS EMBRAPA (2013). Antes do início do experimento foram determinadas suas principais características na camada de 0-0,1 m: pH em água (1:1): 5,0; $\mathrm{P}$ disponível: $2,6 \mathrm{mg} \mathrm{kg}^{-1} ; \mathrm{K}$ trocável: $178 \mathrm{mg} \mathrm{kg}^{-1}$; Ca trocável: $5,7 \mathrm{cmol}_{\mathrm{c}} \mathrm{kg}^{-1} ; \mathrm{Mg}$ trocável: $1,8 \mathrm{cmol}_{\mathrm{c}}$ $\mathrm{kg}^{-1}$; Al trocável: $0,8 \mathrm{cmol}_{\mathrm{c}} \mathrm{kg}^{-1}$; areia: $133 \mathrm{~g} \mathrm{~kg}^{-1}$; silte: $446 \mathrm{~g} \mathrm{~kg}^{-1}$; argila: $421 \mathrm{~g} \mathrm{~kg}^{-1}$ (classe textural argilo siltosa); C orgânico total: $18 \mathrm{~g} \mathrm{~kg}^{-1}$; densidade do solo: $1,28 \mathrm{~kg} \mathrm{dm}^{-3}$; macroporos: $0,09 \mathrm{~m}^{3} \mathrm{~m}^{-3}$; e microporos: $0,43 \mathrm{~m}^{3} \mathrm{~m}^{-3}$. Na Tabela 1 constam os principais dados climáticos da região registrados durante o período de condução do experimento no campo.

Aárea experimental, historicamente com campo natural, foi cultivada durante 15 anos e, nos últimos 10 anos, a semeadura das espécies foi realizada sem prévio revolvimento do solo. Em junho de 2013, após cultivo de feijão, foi realizada a correção da acidez 
Tabela 1 - Dados climáticos registrados durante o período de condução do experimento e na média dos últimos 10 anos, no Planalto Sul Catarinense.

Table 1 - Climate data recorded during the experimental period and the average of the last 10 years, in the southern plateau of Santa Catarina.

\begin{tabular}{|c|c|c|c|c|c|c|c|}
\hline \multirow[b]{2}{*}{ Mês/ano } & \multicolumn{2}{|c|}{ Precipitação (mm) } & \multicolumn{2}{|c|}{ Temp. máx. média $\left({ }^{\circ} \mathrm{C}\right)$} & \multicolumn{2}{|c|}{ Temp. mín. média $\left({ }^{\circ} \mathrm{C}\right)$} & \multirow{2}{*}{$\begin{array}{l}\text { Umidade } \\
\text { relativa média } \\
\text { do ar }(\%)\end{array}$} \\
\hline & Registrado & $\begin{array}{l}\text { Média } 10 \\
\text { anos }\end{array}$ & Registrado & $\begin{array}{l}\text { Média } 10 \\
\text { anos }\end{array}$ & Registrado & $\begin{array}{l}\text { Média } 10 \\
\text { anos }\end{array}$ & \\
\hline $06 / 2013$ & 199,3 & 97,7 & 17,3 & 17,1 & 7,8 & 10,2 & 89,7 \\
\hline $07 / 2013$ & 77,0 & 138,0 & 16,9 & 15,2 & 5,2 & 5,8 & 85,2 \\
\hline $08 / 2013$ & 318,2 & 265,5 & 17,6 & 15,8 & 6,0 & 6,9 & 83,8 \\
\hline $09 / 2013$ & 221,3 & 117,0 & 19,4 & 19,5 & 9,0 & 9,3 & 82,6 \\
\hline $10 / 2013$ & 136,9 & 192,0 & 20,7 & 20,1 & 10,5 & 12,8 & 82,2 \\
\hline $11 / 2013$ & 146,1 & 86,0 & 23,3 & 24,2 & 12,4 & 13,3 & 80,5 \\
\hline $\begin{array}{l}\text { Acumulado* } \\
\text { Média* }^{* *}\end{array}$ & $1.098,8^{*}$ & $896,2^{*}$ & $19,2^{* *}$ & $18,7^{* *}$ & $8,5^{* *}$ & $9,7^{* *}$ & $84,0^{* *}$ \\
\hline
\end{tabular}

Fonte: Inmet (2014).

do solo com aplicação superficial de $10 \mathrm{Mg} \mathrm{ha}^{-1}$ de calcário dolomítico (PRNT 80\%) para elevar o pH a 6,0 (CQFS - RS/SC 2004) e em julho de 2013 foram instalados os tratamentos.

Os tratamentos constituíram-se por diferentes espécies vegetais, sendo eles: POpousio correspondente à vegetação espontânea com predomínio das espécies Sonchus oleraceus L., Lolium multiflorum e Trifolium repens; AP - aveia preta (Avena strigosa); NF - nabo forrageiro (Raphanus sativus L.); EC - ervilhaca comum (Vicia sativa); e CE - consórcio de aveia preta, nabo forrageiro e ervilhaca comum. O delineamento experimental foi de blocos ao acaso, com duas repetições dentro de cada um dos dois blocos, totalizando quatro repetições por tratamento e 20 unidades experimentais com dimensões de $3 \times 10$ m cada uma.

As espécies foram semeadas utilizando-se semeadora mecanizada e espaçamento entre linhas de $0,22 \mathrm{~m}$. Nos tratamentos AP, EC e NF foram utilizados, respectivamente, 80 ; 80 ; e $25 \mathrm{~kg} \mathrm{ha}^{-1}$ de sementes. No CE foi utilizada uma mistura de 30; 40; e $10 \mathrm{~kg} \mathrm{ha}^{-1} \mathrm{de}$ sementes de aveia, ervilhaca e nabo, respectivamente. Os tratamentos AP, EC, NF e CE receberam $150 \mathrm{~kg}$ ha $^{-1}$ de superfosfato triplo $\left(41 \% \mathrm{P}_{2} \mathrm{O}_{5}\right)$. No AP e NF foram aplicados $45 \mathrm{~kg} \mathrm{ha}^{-1}$ de ureia $(45 \% \mathrm{~N})$ no ato da semeadura e $90 \mathrm{~kg} \mathrm{ha}^{-1}$ após 50 dias. Nos tratamentos EC e CE não foi aplicado $\mathrm{N}$ pelo fato da ervilhaca apresentar fixação biológica de N. A quantidade de fertilizantes aplicados seguiu as recomendações de CQFS - RS/SC (2004). No PO não houve aplicação de adubo, pelo fato de ser considerado a testemunha. O controle de espécies invasoras durante o período experimental foi realizado por meio de arranquio manual, com exceção do tratamento PO, mantido com vegetação espontânea.

Para as avaliações foram definidas três subáreas distintas dentro de cada parcela. Em cada uma delas demarcou-se um quadro de 0,6 x 0,6 m $\left(0,36 \mathrm{~m}^{2}\right)$, contendo três fileiras de plantas cada. A avaliação de altura de plantas foi realizada a cada 15 dias, após a emergência das mesmas. Para isso, utilizou-se uma trena, efetuando-se 18 leituras por subárea, perfazendo um total de 54 leituras por parcela no somatório dos três locais distintos. A cobertura do solo pela parte aérea das plantas foi realizada nas mesmas épocas das determinações de altura de plantas, com auxílio de uma máquina fotográfica digital, tendo sido capturada uma imagem de cada subárea dentro das parcelas, a uma distância vertical de um metro do alvo. Tal distância foi escolhida com intuito de padronizar a dimensão das imagens para posterior processamento pelo software $\mathrm{SisCob}^{\circledR}$, desenvolvido pela Embrapa (JORGE \& SILVA 2009), obtendo-se a porcentagem de cobertura do solo pelo dossel das plantas.

No momento em que as culturas atingiram o pleno florescimento, efetuou-se a coleta da parte aérea das plantas para quantificar a produção de fitomassa. Para isso, foi feito o corte rente ao solo de toda a massa vegetal de cada uma das três subáreas de cada parcela. Posteriormente efetuou-se a pesagem para quantificar a massa verde e em seguida o material foi levado à estufa com circulação forçada de ar a $65^{\circ} \mathrm{C}$ para determinar sua massa seca, conforme metodologia de TEDESCO et al. (1995).

Após amostragem da parte aérea procedeu- 
se a coleta para quantificação da massa de raízes, de acordo com metodologia descrita por VOLK \& COGO (2008). Para isso utilizou-se um trado cilíndrico com $0,055 \mathrm{~m}$ de diâmetro, coletando-se amostras de solo na profundidade de $0-0,2 \mathrm{~m}$, sendo um ponto na linha e dois nas entrelinhas das plantas, em três locais por parcela. Procedeu-se a separação de solo e raízes, as quais foram lavadas e tamisadas em peneira com malha de $0,5 \mathrm{~mm}$ e secas em estufa com circulação forçada de ar a $65^{\circ} \mathrm{C}$ para quantificação da massa seca de raízes.

Amostras de parte aérea e raízes secas e moídas foram submetidas à digestão ácida de tecido vegetal, realizada com $\mathrm{H}_{2} \mathrm{O}_{2}$ e $\mathrm{H}_{2} \mathrm{SO}_{4}$ pelo método descrito por TEDESCO et al. (1995). Com as alíquotas obtidas determinou-se o $\mathrm{N}$ total por destilação e arraste de vapores em aparelho semimicro Kjeldahl, o P através de leitura em espectrofotômetro de absorção molecular na região visível em $660 \mathrm{~nm}$, o K por leitura em espectrofotômetro de emissão atômica e o $\mathrm{Ca}$ e $\mathrm{Mg}$ por leitura em espectrofotômetro de absorção atômica em chama. $\mathrm{O}$ acúmulo dos nutrientes em cada tratamento foi calculado pelo produto entre o teor do elemento no tecido vegetal e a quantidade de biomassa vegetal seca produzida.

Os dados foram submetidos à análise de variância e as médias dos tratamentos foram comparadas pelo teste de Tukey $(\mathrm{p}<0,05)$.

\section{RESULTADOS E DISCUSSÃO}

A altura e a porcentagem de cobertura do solo pelo dossel das plantas variaram em função dos tratamentos (Figura 1). O menor crescimento em altura foi observado para $\mathrm{PO}$ em todas as avaliações e para EC até os 75 DAE (dias após emergência das plantas). Os tratamentos AP, NF e CE apresentaram maior estatura, tendo comportamento semelhante entre si até os 60 DAE.

Nos tratamentos PO e NF as avaliações foram encerradas aos $90 \mathrm{DAE}$, pelo fato das plantas terem atingido pleno florescimento, expressando estatura final, respectivamente, de 22 e $92 \mathrm{~cm}$. Para AP, CE e EC foi realizada avaliação aos $105 \mathrm{DAE}$, constatandose estatura, respectivamente, de 118,95 e $63 \mathrm{~cm}$. Conforme LUCIANO et al. (2009), a aveia preta apresenta crescimento acelerado e maior estatura. Esta característica se deve a sua morfologia, com colmo cilíndrico, ereto, glabro e composto por nós e entrenós que lhe conferem maior sustentação (FONTANELI et al. 2009). Por outro lado, leguminosas como a ervilhaca possuem menor estatura devido ao seu hábito de crescimento prostrado (ALCÂNTARA \& BUFARAH 1992).

A cobertura do solo pelo dossel vegetativo foi significativamente menor no PO, atingindo cobertura máxima de 59\% aos 90 DAE (Figura 1). DERPSCH et al. (1991) destaca que o pousio de inverno não oferece adequada proteção ao solo pelo crescimento geralmente reduzido de plantas espontâneas e, consequentemente, deixa o solo exposto à erosão e perda de nutrientes. No início do desenvolvimento, aos 30 DAE, os tratamentos NF e CE apresentaram cobertura média de $27 \%$, valor este superior ao proporcionado pelo AP e EC (média de 19\%) e PO (5\%). Conforme SANTOS \& REIS (2003), o nabo forrageiro se caracteriza pelo crescimento inicial extremamente rápido, o que justifica tal comportamento.

Aos 60 DAE o cultivo de AP cobriu 54\% da superfície do solo, sendo inferior aos tratamentos NF, EC e CE, com cobertura, respectivamente, de 71, 81 e $84 \%$. Aos $90 \mathrm{DAE}$, nos tratamentos com ervilhaca (EC e CE) as plantas apresentaram maior capacidade em cobrir o solo, com valor médio de $99,7 \%$. De acordo com ROS \& AITA (1996), a ervilhaca comum, embora manifeste menor crescimento inicial que outras espécies, têm capacidade de cobrir até 100\% da superfície do solo ao final do ciclo. Para esta mesma época de avaliação a cobertura proporcionada pelo AP e NF foi, respectivamente, de 93 e $89 \%$, demonstrando estas espécies ter bom potencial para cobertura do solo. Nos tratamentos EC e CE constatou-se aos 105 DAE valores iguais de porcentagem de cobertura obtidos aos $90 \mathrm{DAE}$, enquanto AP teve uma redução de $0,3 \%$ na cobertura do solo.

A taxa de incremento na porcentagem de cobertura do solo foi maior entre 45 e 60 DAE para EC, CE e NF, com aumento, respectivamente, de 3,1; 2,7 ; e $2,2 \%$ ao dia, entre 45 e 75 DAE para AP $(1,6 \%$ ao dia) e entre 60 e 75 DAE para PO (1,5\% ao dia). No geral, as plantas de cobertura testadas, com exceção do PO, foram eficientes em cobrir o solo durante o seu período vegetativo. No entanto o $\mathrm{CE}$, possivelmente pela interação positiva entre diferentes espécies, teve um melhor desempenho, pois apresentou desenvolvimento inicial rápido e cobriu praticamente toda a superfície do solo ao final.

Os cultivos de AP, EC e CE expressaram maior rendimento de massa seca de parte aérea, 

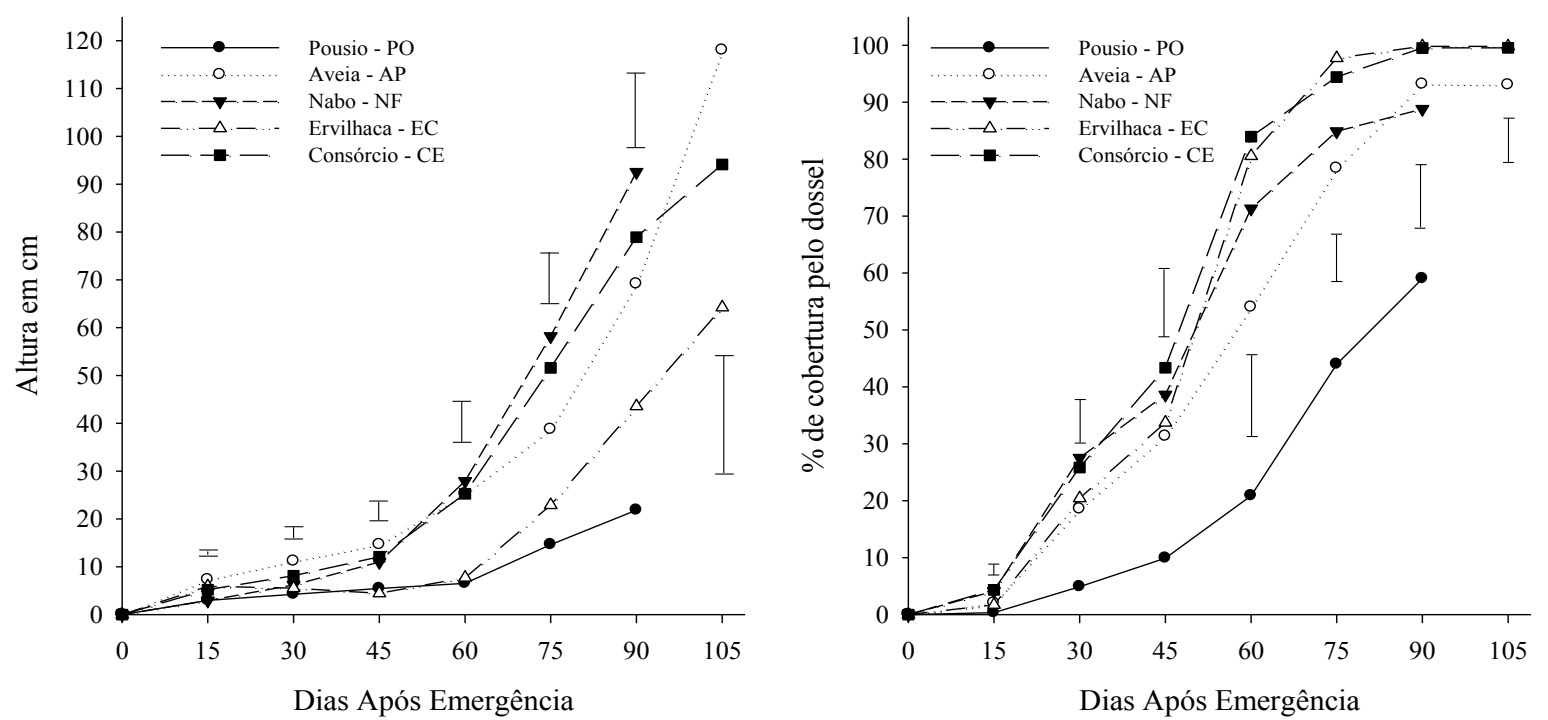

Figura 1 - Altura de plantas $(\mathrm{cm})$ e cobertura do solo pelo dossel vegetativo (\%) em função dos dias após a emergência, em diferentes tratamentos no Planalto Sul Catarinense. As barras verticais representam a diferença mínima significativa das médias dos tratamentos em cada época de avaliação, pelo teste de Tukey $(\mathrm{p}<0,05)$.

Figure 1 - Plant height (cm) and soil cover by canopy (\%) as a function of days after emergence, in different treatments in the southern plateau of Santa Catarina. Vertical bars represent the least significant difference of treatment means at each evaluation time, by Tukey test $(p<0.05)$.

respectivamente, de 9,91, 9,14 e 9,68 $\mathrm{Mg} \mathrm{ha}^{-1}$. Os tratamentos PO e NF apresentaram produção, respectivamente, de 1,88 e 4,26 $\mathrm{Mg} \mathrm{ha}^{-1}$, o que correspondeu a 20 e $45 \%$ do obtido pela média dos demais tratamentos (Tabela 2). Do ponto de vista conservacionista, considera-se a quantidade mínima de $6 \mathrm{Mg} \mathrm{ha}^{-1}$ de massa seca produzida pela parte área das plantas para proporcionar adequada cobertura do solo por resíduos vegetais em semeadura direta (ALVARENGA et al. 2001). Os tratamentos AP, EC e CE mostraram-se eficientes neste aspecto, enquanto $\mathrm{PO}$ e NF apresentaram déficit de produção, respectivamente, de 4,12 e 1,74 $\mathrm{Mg} \mathrm{ha}^{-1}$.

Em estudo realizado por CARVALHO et al. (2007), os autores observaram produção inferior de plantas de cobertura em um Gleissolo Melânico no estado do Paraná, variando de 2,47 $\mathrm{Mg} \mathrm{ha}^{-1}$ no nabo forrageiro a 4,63 $\mathrm{Mg} \mathrm{ha}^{-1}$ na aveia preta. PÖTTKER \& ROMAN (1994) obtiveram produção máxima equivalente a $72 \%$ para aveia e $55 \%$ para ervilhaca comparado ao apresentado neste trabalho, em um Latossolo Vermelho no estado do Rio Grande do Sul. DONEDA et al. (2012) obtiveram, para o nabo forrageiro, $8,3 \mathrm{Mg} \mathrm{ha}^{-1}$, seguido da ervilha forrageira e da aveia preta, com 5,5 e 3,3 $\mathrm{Mg} \mathrm{ha}^{-1}$, respectivamente. Já a menor produção no $\mathrm{PO}$ está de acordo com resultados obtidos por AITA et al. (2001), DONEDA et al. (2012) e LÁZARO et al. (2013), explicadas pela ausência de adubação e pela baixa capacidade das espécies espontâneas em produzir biomassa.

As diferenças observadas em relação a outros trabalhos podem ser explicadas pelo fato de que na presente pesquisa os tratamentos foram adubados, exceto o PO, objetivando expressar sua máxima capacidade de produção, o que ocorre em situações de solo com níveis de fertilidade adequados. BERTOL et al. (2014), avaliando a produção de massa seca de diferentes espécies vegetais, incluindo plantas de cobertura, concluíram que o aumento de $25 \%$ para $100 \%$ da dose recomendada de fertilizantes elevou a produção média de fitomassa em 35\%. Segundo AGOSTINETTO et al. (2000), diferenças no comportamento das espécies vegetais também podem ocorrer devido a fatores climáticos, edáficos e ambientais, peculiares de cada região, que interferem no crescimento e na adaptação das espécies. Portanto, as variações dos fatores em uma região podem estimular o desenvolvimento de uma determinada espécie e inibir a outra. Durante a realização desta pesquisa não foram observadas condições climáticas desfavoráveis às plantas, principalmente em relação a precipitação pluviométrica que foi bem distribuída e 
superior à média dos últimos dez anos (Tabela 1).

A produção de massa verde da parte aérea variou entre 11,48 e $53,30 \mathrm{Mg} \mathrm{ha}^{-1}$, tendo maiores rendimentos os cultivos CE eAP (Tabela 2). Da mesma forma que ocorreu para massa seca o tratamento PO foi o que apresentou menor massa verde, diferindo dos demais. $\mathrm{O}$ tratamento $\mathrm{EC}$ apresentou produção superior ao NF.

A produção de massa seca de raízes na camada de $0-0,2 \mathrm{~m}$ de profundidade do solo variou entre 1,35 e $4,53 \mathrm{Mg} \mathrm{ha}^{-1}$ (Tabela 2). Maior massa de raízes ocorreu no tratamento AP, seguido pelos tratamentos CE e EC. O tratamento PO que apresentou numericamente a menor produção, não diferiu estatisticamente do NF. Em comparação ao AP que teve maior rendimento, a produção foi equivalente a $67,53,41$ e $30 \%$ no $\mathrm{CE}$, EC, NF e PO, respectivamente. ROS \& AITA (1996) também observaram maior massa de raízes no cultivo de aveia preta em relação a outras espécies de plantas de cobertura de inverno. De acordo com LUCIANO et al. (2009), as raízes das gramíneas melhoram a agregação do solo na região de sua abrangência, em razão da alta densidade de raízes finas que promovem a aproximação das partículas de solo e aumentam a estabilidade de agregados em relação as raízes de leguminosas. Ainda, segundo BALESDENT \& BALABANE (1996), o desenvolvimento radicular é importante, pois proporciona maiores teores de $\mathrm{C}$ orgânico no solo em relação a parte aérea, devido a sua biodegradação ser relativamente lenta. A contribuição das raízes das plantas de cobertura na massa seca total produzida (parte aérea + raízes) foi expressiva, correspondendo a $31,24,21,30$ e $42 \%$ do total nos tratamentos AP, CE, EC, NF e PO, respectivamente.

Embora $\mathrm{CE}$ tenha produzido menor massa de raízes em relação a $\mathrm{AP}$, a produção total de massa seca, incluindo parte aérea e raízes, foi semelhante estatisticamente entre os dois tratamentos (Tabela 2). De acordo com BONJORNO et al. (2010) o desempenho satisfatório do consórcio deve-se ao efeito de complementaridade entre as diferentes espécies utilizadas. A ervilhaca promove a fixação biológica de nitrogênio, disponibilizando este nutriente no solo e favorecendo o desenvolvimento da aveia preta e do nabo forrageiro que servem de suporte para o seu crescimento. Por apresentarem diferenças quanto ao ciclo de desenvolvimento, área de exploração radicular, capacidade de competição e exigência nutricional, elas não competem entre si pelos fatores indispensáveis ao desenvolvimento.

Os maiores acúmulos de nutrientes na parte aérea das plantas ocorreram nos tratamentos EC e $\mathrm{CE}$, sendo, na média, $8 ; 6 ; 5 ; 5$; e 4 vezes maiores que $\mathrm{PO}$, em relação aos elementos $\mathrm{N}, \mathrm{K}, \mathrm{Ca}, \mathrm{P}$ e Mg, respectivamente (Tabela 3). Os maiores valores de $\mathrm{N}$, $\mathrm{K}$ e $\mathrm{P}$ acumulados pelas plantas nestes tratamentos, se justificam pela alta produção de massa seca de parte aérea (Tabela 2) e pelos maiores teores destes elementos no tecido vegetal (Tabela 3). Os teores de $\mathrm{Ca}$ e $\mathrm{Mg}$ não apresentaram o mesmo comportamento, sendo maiores no cultivo de NF. No entanto, o acúmulo destes elementos foi menor neste tratamento do que naqueles em função da menor produção de massa seca de parte aérea. Os tratamentos AP e NF também demonstraram boa eficiência em acumular $\mathrm{K}$ e Ca, respectivamente.

Os maiores teores na parte aérea de $\mathrm{N}$ e $\mathrm{K}$ no tratamento EC, de $\mathrm{P}$ nos tratamentos $\mathrm{EC}$ e $\mathrm{CE}$ e de $\mathrm{Ca}$ e Mg no tratamento NF estão de acordo com os apresentados por CALEGARI et al. (1993), os quais

Tabela 2 - Biomassa vegetal verde de parte aérea e massa seca da parte aérea e raízes de diferentes plantas de cobertura, em Mg ha ${ }^{-1}$, no Planalto Sul Catarinense.

Table 2 - Fresh biomass of shoots and dry matter of shoots and roots of different cover crops, in $\mathrm{Mg} \mathrm{ha}^{-1}$, in the southern plateau of Santa Catarina.

\begin{tabular}{|c|c|c|c|c|}
\hline \multirow{3}{*}{ Tratamento } & \multirow{2}{*}{ Matéria verde } & \multicolumn{3}{|l|}{ Massa seca } \\
\hline & & Parte aérea & Raízes & Total \\
\hline & \multicolumn{4}{|c|}{ 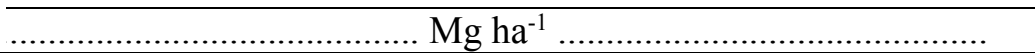 } \\
\hline Pousio & $11,48 \mathrm{~d}$ & $1,88 \mathrm{c}$ & $1,35 \mathrm{~d}$ & $3,23 \mathrm{~d}$ \\
\hline Aveia & $45,46 \mathrm{ab}$ & $9,91 \mathrm{a}$ & $4,53 \mathrm{a}$ & 14,44 a \\
\hline Nabo & $30,46 \mathrm{c}$ & $4,26 \mathrm{~b}$ & $1,86 \mathrm{~cd}$ & $6,12 \mathrm{c}$ \\
\hline Ervilhaca & $40,65 \mathrm{~b}$ & $9,14 \mathrm{a}$ & $2,41 \mathrm{bc}$ & $11,55 \mathrm{~b}$ \\
\hline Consórcio & $53,30 \mathrm{a}$ & $9,68 \mathrm{a}$ & $3,02 \mathrm{~b}$ & $12,70 \mathrm{ab}$ \\
\hline CV $(\%)$ & 12,4 & 14,4 & 16,1 & 12,6 \\
\hline
\end{tabular}

Médias seguidas pela mesma letra na coluna não diferem entre si pelo teste de Tukey $(\mathrm{p}<0,05)$. 
Tabela 3 - Teores $(\%)$ e acúmulo $\left(\mathrm{kg} \mathrm{ha}^{-1}\right)$ de nutrientes na parte aérea e nas raízes de diferentes plantas de cobertura, no Planalto Sul Catarinense.

Table 3 - Levels (\%) and accumulation $\left(\mathrm{kg} \mathrm{ha}^{-1}\right)$ of nutrients in the shoots and roots of different cover crops, in the southern plateau of Santa Catarina.

\begin{tabular}{|c|c|c|c|c|c|}
\hline \multirow{2}{*}{ Tratamento } & \multicolumn{5}{|c|}{ Teor na massa seca de parte aérea (\%) } \\
\hline & $\mathrm{Ca}$ & $\mathrm{Mg}$ & $\mathrm{P}$ & $\mathrm{K}$ & $\mathrm{N}$ \\
\hline Pousio & $1,00 \mathrm{~b}$ & $0,625 \mathrm{~b}$ & $0,325 \mathrm{ab}$ & $3,06 \mathrm{bc}$ & $0,94 \mathrm{~d}$ \\
\hline Aveia & $0,42 \mathrm{c}$ & $0,383 \mathrm{~d}$ & $0,200 \mathrm{c}$ & $2,83 \mathrm{~cd}$ & $1,51 \mathrm{c}$ \\
\hline Nabo & $1,95 \mathrm{a}$ & $0,835 \mathrm{a}$ & $0,250 \mathrm{bc}$ & $2,63 \mathrm{~d}$ & $1,74 \mathrm{c}$ \\
\hline Ervilhaca & $0,96 \mathrm{~b}$ & $0,510 \mathrm{c}$ & $0,400 \mathrm{a}$ & $3,91 \mathrm{a}$ & $2,86 \mathrm{a}$ \\
\hline Consórcio & $1,00 \mathrm{~b}$ & $0,555 \mathrm{bc}$ & $0,325 \mathrm{ab}$ & $3,28 \mathrm{~b}$ & $2,20 \mathrm{~b}$ \\
\hline CV $(\%)$ & 13,8 & 6,5 & 11,6 & 6,1 & 9,0 \\
\hline \multirow{2}{*}{ Tratamento } & \multicolumn{5}{|c|}{ Teor na massa seca de raízes (\%) } \\
\hline & $\mathrm{Ca}$ & $\mathrm{Mg}$ & $\mathrm{P}$ & $\mathrm{K}$ & $\mathrm{N}$ \\
\hline Pousio & $0,063 \mathrm{ab}$ & $0,215 \mathrm{a}$ & $0,200 \mathrm{a}$ & $1,12 \mathrm{bc}$ & $1,53 \mathrm{~b}$ \\
\hline Aveia & $0,035 \mathrm{~b}$ & $0,170 \mathrm{~b}$ & $0,100 \mathrm{~b}$ & $1,38 \mathrm{ab}$ & $0,78 \mathrm{~d}$ \\
\hline Nabo & $0,063 \mathrm{ab}$ & $0,215 \mathrm{a}$ & $0,130 \mathrm{~b}$ & $1,50 \mathrm{a}$ & $1,27 \mathrm{bc}$ \\
\hline Ervilhaca & $0,083 \mathrm{a}$ & $0,243 \mathrm{a}$ & $0,200 \mathrm{a}$ & $0,99 \mathrm{c}$ & $1,99 \mathrm{a}$ \\
\hline Consórcio & $0,068 \mathrm{ab}$ & $0,238 \mathrm{a}$ & $0,100 \mathrm{~b}$ & $1,62 \mathrm{a}$ & $1,07 \mathrm{~cd}$ \\
\hline $\mathrm{CV}(\%)$ & 28,7 & 7,8 & 15,7 & 10,9 & 12,5 \\
\hline \multirow{2}{*}{ Tratamento } & \multicolumn{5}{|c|}{ Acúmulo na parte aérea $\left(\mathrm{kg} \mathrm{ha}^{-1}\right)$} \\
\hline & $\mathrm{Ca}$ & $\mathrm{Mg}$ & $\mathrm{P}$ & $\mathrm{K}$ & $\mathrm{N}$ \\
\hline Pousio & $18,8 \mathrm{~b}$ & $11,7 \mathrm{c}$ & $6,3 \mathrm{~d}$ & $57,4 \mathrm{~b}$ & $28,2 \mathrm{~b}$ \\
\hline Aveia & $41,4 \mathrm{~b}$ & $37,6 \mathrm{~b}$ & $19,5 \mathrm{bc}$ & $280,4 \mathrm{a}$ & $91,6 \mathrm{~b}$ \\
\hline Nabo & $84,5 \mathrm{a}$ & $35,6 \mathrm{~b}$ & $10,5 \mathrm{~cd}$ & $112,8 \mathrm{~b}$ & $74,6 \mathrm{~b}$ \\
\hline Ervilhaca & 88,8 a & $46,7 \mathrm{ab}$ & $36,8 \mathrm{a}$ & $358,4 \mathrm{a}$ & $261,6 \mathrm{a}$ \\
\hline Consórcio & $96,3 \mathrm{a}$ & $53,7 \mathrm{a}$ & $30,5 \mathrm{ab}$ & $315,3 \mathrm{a}$ & $211,2 \mathrm{a}$ \\
\hline CV $(\%)$ & 26,2 & 19,1 & 26,5 & 22,2 & 24,5 \\
\hline \multirow{2}{*}{ Tratamento } & \multicolumn{5}{|c|}{ Acúmulo nas raízes $\left(\mathrm{kg} \mathrm{ha}^{-1}\right)$} \\
\hline & $\mathrm{Ca}$ & $\mathrm{Mg}$ & $\mathrm{P}$ & $\mathrm{K}$ & $\mathrm{N}$ \\
\hline Pousio & $0,85 \mathrm{a}$ & $2,9 \mathrm{c}$ & $2,2 \mathrm{a}$ & $14,7 \mathrm{~b}$ & $21,1 \mathrm{~b}$ \\
\hline Aveia & $1,49 \mathrm{a}$ & $7,8 \mathrm{a}$ & $4,0 \mathrm{a}$ & $63,3 \mathrm{a}$ & $35,8 \mathrm{ab}$ \\
\hline Nabo & $1,16 \mathrm{a}$ & $4,0 \mathrm{bc}$ & $2,5 \mathrm{a}$ & $27,8 \mathrm{~b}$ & $23,6 \mathrm{~b}$ \\
\hline Ervilhaca & $2,08 \mathrm{a}$ & $5,9 \mathrm{ab}$ & $4,2 \mathrm{a}$ & $24,1 \mathrm{~b}$ & $47,8 \mathrm{a}$ \\
\hline Consórcio & $2,09 \mathrm{a}$ & $7,3 \mathrm{a}$ & $3,6 \mathrm{a}$ & $49,3 \mathrm{a}$ & $32,7 \mathrm{ab}$ \\
\hline CV $(\%)$ & 37,3 & 21,3 & 29,6 & 23,1 & 25,6 \\
\hline
\end{tabular}

Médias seguidas pela mesma letra na coluna não diferem entre si pelo teste de Tukey $(\mathrm{p}<0,05)$.

observaram menor concentração de nutrientes nas gramíneas em relação às leguminosas e crucíferas. SOUZA \& GUIMARÃES (2013) observaram maiores teores de $\mathrm{N}$ no tecido vegetal de leguminosa solteira e no consórcio entre gramínea e leguminosa em comparação à gramínea solteira, além de maiores teores de $\mathrm{K}$ no consórcio e na gramínea solteira. No entanto, os mesmos autores ressaltam que os teores nas plantas fornecem informações apenas qualitativas, necessitando da quantidade de massa produzida para se obter o acúmulo, que é melhor indicador para determinar quanto de cada nutriente das plantas de cobertura poderá ser aportado ao solo.

É importante salientar que os tratamentos com utilização de ervilhaca não receberam adubação nitrogenada. Isso demostra a importância do uso desta família botânica pura ou em consórcio para o fornecimento de $\mathrm{N}$ ao solo por meio da fixação biológica. GIACOMINI et al. (2003) obtiveram acúmulo de $\mathrm{N}$ e $\mathrm{P}$ maior nos tratamentos com ervilhaca, mostrando sua eficiência tanto em cultivo isolado quanto em consórcio. Os valores encontrados no presente trabalho foram superiores aos obtidos por estes autores, o que destaca a importância de 
avaliações locais, já que existe forte influência das condições edafoclimáticas no desenvolvimento das plantas de cobertura que, por sua vez, influenciam o acúmulo de nutrientes. Exemplo disso é o estudo realizado por HEINZ et al. (2011), avaliando a cultura do nabo forrageiro sem adubação química em Latossolo Vermelho no estado do Mato Grosso do Sul. Os autores encontraram acúmulos de N, P e K superiores e de $\mathrm{Ca}$ e $\mathrm{Mg}$ inferiores aos encontrados neste estudo. Já CRUSCIOL et al. (2005) observaram valores semelhantes de acúmulo desses nutrientes na parte aérea de nabo forrageiro em um Latossolo Vermelho no Paraná.

Foi possível constatar a capacidade das plantas de cobertura do solo em reciclar o elemento K, pois nenhum dos tratamentos recebeu adubação com este elemento pelo fato de os teores no solo estarem na faixa de suficiência para o desenvolvimento das culturas. Destacam-se o CE e os cultivos solteiros de EC e AP, os quais acumularam entre 280,4 e $358,4 \mathrm{~kg}$ ha $^{-1}$ de K na parte aérea (Tabela 3). De acordo com RIBEIRO et al. (2011), a diversidade de espécies de plantas de cobertura na rotação de culturas e no consórcio de cultivos condiciona o manejo eficiente do solo para a máxima exploração de seu potencial produtivo.

$\mathrm{O}$ acúmulo de nutrientes nas raízes foi menor em relação a parte aérea (Tabela 3). Para os elementos $\mathrm{Ca}$ e $\mathrm{P}$ não houve diferença significativa entre tratamentos, com valores médios, respectivamente, de 1,5 e 3,3 $\mathrm{kg} \mathrm{ha}^{-1}$. O acúmulo de $\mathrm{Mg}$ nas raízes variou entre 2,9 e $7,8 \mathrm{~kg} \mathrm{ha}^{-1}$, maior nos tratamentos AP $\left(7,8 \mathrm{~kg} \mathrm{ha}^{-1}\right)$, EC $\left(5,9 \mathrm{~kg} \mathrm{ha}^{-1}\right)$ e CE $\left(7,3 \mathrm{~kg} \mathrm{ha}^{-1}\right)$. Já o acúmulo de $\mathrm{N}$ e $\mathrm{K}$ foi maior, variando entre 21,1 e 47,8 $\mathrm{kg} \mathrm{ha}^{-1}$ e entre 14,7 e $63,3 \mathrm{~kg} \mathrm{ha}^{-1}$, respectivamente, tendo maiores valores de $\mathrm{N}$ os tratamentos EC $(47,8$ $\left.\mathrm{kg} \mathrm{ha} \mathrm{a}^{-1}\right)$, AP $\left(35,8 \mathrm{~kg} \mathrm{ha}^{-1}\right)$ e CE $\left(32,7 \mathrm{~kg} \mathrm{ha}^{-1}\right)$ e de $\mathrm{K}$ os tratamentos AP $\left(63,3 \mathrm{~kg} \mathrm{ha}^{-1}\right)$ e EC $(49,3 \mathrm{~kg}$ $\left.\mathrm{ha}^{-1}\right)$. Menores acúmulos nas raízes são explicados pela associação de menor produção de massa seca (Tabela 2) e teores baixos no tecido vegetal (Tabela 3), comparativamente à parte aérea. A contribuição das raízes em acumular nutrientes correspondeu a 3, 17, 20 e 19\% ao proporcionado pela parte aérea para os elementos $\mathrm{Ca}, \mathrm{Mg}, \mathrm{P}$ e $\mathrm{K}$, respectivamente, na média dos tratamentos. Para o $\mathrm{N}$ houve maior variação entre tratamentos da proporção acumulada pelas raízes, correspondendo a 75, 39, 32, 18 e 15\% do acumulado pela parte aérea, respectivamente, em $\mathrm{PO}, \mathrm{AP}, \mathrm{NF}, \mathrm{EC}$ e CE.
Os nutrientes acumulados no tecido vegetal, contabilizando o somatório da parte aérea e das raízes, teve a seguinte ordem: $\mathrm{K}>\mathrm{N}>\mathrm{Ca}>\mathrm{Mg}>\mathrm{P}$. No geral, pode-se constatar que o uso de plantas de cobertura do solo na região do Planalto Sul Catarinense tem potencial para alta produção de biomassa vegetal e acúmulo de nutrientes, tornando-se superior ao pousio de inverno, e que o consórcio de espécies é eficiente em produzir biomassa e aportar nutrientes comparativamente aos cultivos solteiros.

\section{CONCLUSÕES}

A cobertura do solo pelo dossel das plantas é influenciada pelo tipo de espécie vegetal e período de crescimento, no início do ciclo é maior nos cultivos de nabo forrageiro e consórcio de espécies (aveia, ervilhaca e nabo) enquanto ao final é maior na ervilhaca comum e no consórcio.

Os cultivos de aveia preta, ervilhaca comum e o consórcio produzem maior massa seca de parte aérea, enquanto a aveia preta produz maior massa de raízes.

Ervilhaca comum e o consórcio são mais eficientes em acumular os elementos $\mathrm{N}, \mathrm{P}, \mathrm{K}, \mathrm{Ca}$ e $\mathrm{Mg}$ no tecido vegetal, no entanto a aveia é boa acumuladora de $\mathrm{K}$ e $\mathrm{Mg}$ e o nabo forrageiro de $\mathrm{Ca}$, a parte aérea é responsável pelo maior acúmulo em comparação as raízes concentradas na profundidade de $0-0,20 \mathrm{~m}$.

\section{REFERÊNCIAS}

AGOSTINETTO D et al. 2000. Adaptação de espécies utilizadas para cobertura de solo no Sul do Rio Grande do Sul. Revista Brasileira de Agrociência 6: 47-52.

AITA C et al. 2001. Plantas de cobertura de solo como fonte de nitrogênio ao milho. Revista Brasileira de Ciência do Solo 25: 157-165.

ALBUQUERQUE AW et al. 2013. Plantas de cobertura e adubação nitrogenada na produção de milho em sistema de plantio direto. Revista Brasileira de Engenharia Agrícola e Ambiental 17: 721-726.

ALCÂNTARA FA et al. 2000. Adubação verde na recuperação da fertilidade de um Latossolo VermelhoEscuro degradado. Pesquisa Agropecuária Brasileira 35: 277-288.

ALCÂNTARA PB \& BUFARAH G. 1992. Plantas forrageiras: gramíneas e leguminosas. 4.ed. São Paulo: Nobel. 162p.

ALVARENGA RC et al. 2001. Plantas de cobertura de solo para sistema plantio direto. Informe Agropecuário 22: 2536. 
ALVARES CA et al. 2013. Koppen's climate classification map for Brazil. Meteorologische Zeitschrif 22: 711-728. BALESDENT J \& BALABANE M. 1996. Major contribution of roots to soil carbon storage inferred from maize cultivated soils. Soil Biology and Biochemistry 28: 1261-1263.

BERTOL I et al. 2014. Soil water erosion under different cultivation systems and different fertilization rates and forms over 10 years. Revista Brasileira de Ciência do Solo 38: 1918-1928.

BERTOL I et al. 2014. Manejo e conservação do solo e da água no Brasil: retrospectiva e projeção para o futuro. In: LEITE LFC et al. Agricultura conservacionista no Brasil. Brasília: Embrapa. p.43-68.

BEZERRA AS \& CANTALICE JRB. 2006. Erosão entre sulcos em diferentes condições de cobertura do solo, sob cultivo de cana-de-açúcar. Revista Brasileira de Ciência do Solo 30: 565-573.

BONJORNO II et al. 2010. Efeito de plantas de cobertura de inverno sobre cultivo de milho em sistema de plantio direto. Revista Brasileira de Agroecologia 5: 99-108.

CALEGARI A et al. 1993. Adubação verde no sul do Brasil. 2.ed. Rio de Janeiro: AS-PTA. 346p.

CARVALHO IQ et al. 2007. Espécies de cobertura de inverno e nitrogênio na cultura do milho em sistema de plantio direto. Scientia Agraria 8: 179-184.

COMISSÃO DE QUÍMICA E FERTILIDADE DO SOLO - CQFS-RS/SC. 2004. Manual de adubação e calagem para os estados do Rio Grande do Sul e de Santa Catarina. 10 ed. Porto Alegre, 400p.

CRUSCIOL CAC et al. 2005. Persistência de palhada e liberação de nutrientes do nabo forrageiro no plantio direto. Pesquisa Agropecuária Brasileira 40: 161-168.

DERPSCH R et al. 1991. Controle de erosão no Paraná, Brasil: sistemas de cobertura do solo, plantio direto e preparo conservacionista do solo. Eschborn: GTZ. 272p.

DONEDA A et al. 2012. Fitomassa e decomposição de resíduos de plantas de cobertura puras e consorciadas. Revista Brasileira de Ciência do Solo 36: 1714-1723. EMBRAPA - EMPRESA BRASILEIRA DE PESQUISA AGROPECUÁRIA. 2013. Sistema brasileiro de classificação de solos. 3. ed. Brasília: Embrapa. 353p.

FONTANELI RS et al. 2009. Rendimento e valor nutritivo de cereais de inverno de duplo propósito: forragem verde e silagem ou grãos. Revista Brasileira de Zootecnia 38: 2116-2120.

GIACOMINI SJ et al. 2003. Matéria seca, relação C/N e acúmulo de nitrogênio, fósforo e potássio em misturas de plantas de cobertura de solo. Revista Brasileira de Ciência do Solo 27: 325-334.

HEINZ R et al. 2011. Decomposição e liberação de nutrientes de resíduos culturais de crambe e nabo forrageiro. Ciência Rural 41: 1549-1555.

INMET. 2014. Banco de dados meteorológicos para ensino e pesquisa. Brasília: Inmet. Disponível em: http://www. inmet.gov.br/portal/index.php?r=bdmep/bdmep. Acesso em: 15 fev. 2014.

JORGE LAC \& SILVA DJCB. 2009. SisCob: manual de utilização. 1.ed. São Carlos: Embrapa Instrumentação Agropecuária. 18p.

LÁZARO RL et al. 2013. Produtividade de milho cultivado em sucessão à adubação verde. Pesquisa Agropecuária Tropical 43: 10-17.

LUCIANO RV et al. 2009. Perdas de água e solo por erosão hídrica em duas direções de semeadura de aveia e ervilhaca. Revista Brasileira de Ciência do Solo 33: 669-676.

PÖTTKER D \& ROMAN ES. 1994. Efeito de resíduos de culturas e do pousio de inverno sobre a resposta do milho a nitrogênio. Pesquisa Agropecuária Brasileira 29: 763-770.

REIS RJA et al. 2012. Efeitos de plantas de cobertura nas associações do milho (Zea mays L.) com fungos benéficos do solo. Revista Brasileira de Agropecuária Sustentável 2: 75-80.

RIBEIRO PH et al. 2011. Adubação verde, os estoques de carbono e nitrogênio e a qualidade da matéria orgânica do solo. Revista Verde 6: 43-50.

RIZZARDI MA et al. 2006. Controle de plantas daninhas em milho em função de quantidades de palha de nabo forrageiro. Planta Daninha 24: 263-270.

ROS CO \& AITA C. 1996. Efeito de espécies de inverno na cobertura do solo e fornecimento de nitrogênio ao milho em plantio direto. Revista Brasileira de Ciência do Solo 20: 135-140.

ROSSETTI KV et al. 2012. Atributos físicos do solo em diferentes condições de cobertura vegetal em área de plantio direto. Revista Brasileira de Ciências Agrárias 7: 427-433.

SANTOS HP dos \& REIS EM. 2003. Rotação de culturas em plantio direto. 2. ed. Passo Fundo: Embrapa trigo. 212p. SILVA EC et al. 2014. Adubação verde como fonte de nutrientes às culturas. In: LIMA FILHO OF et al. Adubação verde e plantas de cobertura no Brasil: fundamentos e prática. 1.ed. Brasília: Embrapa. p.267-305.

SILVA PRF et al. 2006. Estratégias de manejo de coberturas de solo no inverno para cultivo do milho em sucessão no sistema semeadura direta. Ciência Rural 36: 1011-1020.

SOUZA JL \& GUIMARÃES GP. 2013. Rendimento de massa de adubos verdes e o impacto na fertilidade do solo em sucessão de cultivos orgânicos. Bioscience Journal 29: 1796-1805.

SOUZA LS et al. 2014. Adubação verde na física do solo. In: LIMA FILHO OF et al. Adubação verde e plantas de cobertura no Brasil: fundamentos e prática. 1.ed. Brasília: Embrapa. p.337-369.

TEDESCO MJ et al. 1995. Análise de solo, plantas e outros materiais. 2. ed. Porto Alegre: UFRGS. 174p.

VOLK LBS \& COGO NP. 2008. Inter-relação biomassa vegetal subterrânea-estabilidade de agregados-erosão hídrica em solo submetido a diferentes formas de manejo. Revista Brasileira de Ciência do Solo 32: 1713-1722. 
WOLSCHICK NH. 2014. Desempenho de plantas de cobertura e influência nos atributos do solo e na produtividade de culturas em sucessão. Dissertação (Mestrado em Ciência do Solo). Lages: UDESC. 93p. 